\title{
Mass treatment to eliminate tuberculosis from an island population
}

\author{
P. C. Hill, ${ }^{*}$ C. Dye, ${ }^{\dagger}$ K. Viney, ${ }^{\ddagger}$ K. Tabutoa, ${ }^{\S \dagger}$ T. Kienene, $^{\S}$ K. Bissell, ${ }^{7 \#}$ B. G. Williams, ${ }^{* *}$ R. Zachariah, ${ }^{\dagger \dagger}$ \\ B. J. Marais, ${ }^{\neq \neq}$A. D. Harries \\ *Centre for International Health, Department of Preventive and Social Medicine, Faculty of Medicine, University of \\ Otago, Dunedin, New Zealand; 'HIV/AIDS, Tuberculosis, Malaria \& Neglected Tropical Diseases Cluster, World \\ Health Organization, Geneva, Switzerland; 'Public Health Division, Secretariat of the Pacific Community, Noumea \\ Cedex, New Caledonia; ${ }^{\S}$ National Tuberculosis Control Programme, Ministry of Health and Medical Services, \\ Republic of Kiribati; "International Union Against Tuberculosis and Lung Disease, Paris, France; School of \\ Population Health, University of Auckland, Auckland, New Zealand; **South African Centre for Epidemiological \\ Modelling and Analysis, Cape Town, South Africa; ${ }^{+t}$ Médecins Sans Frontières, Brussels Operational Centre, \\ Luxembourg, Belgium; ${ }^{\ddagger \neq}$ Sydney Emerging Infectious Disease and Biosecurity Institute and Centre for Research \\ Excellence in Tuberculosis, University of Sydney, Sydney, New South Wales, Australia; §§London School of Hygiene \\ \& Tropical Medicine, London, UK
}

SU M M A R Y

SETTING: The global target of tuberculosis (TB) elimination by 2050 requires new approaches. Active case finding plus mass prophylactic treatment has been disappointing. We consider mass full anti-tuberculosis treatment as an approach to TB elimination in Kiribati, a Pacific Island nation, with a persistent epidemic of high TB incidence.

OBJECTIVE: To construct a mathematical model to predict whether mass treatment with a full course of anti-tuberculosis drugs might eliminate TB from the defined population of the Republic of Kiribati.

METHODS: We constructed a seven-state compartmental model of the life cycle of Mycobacterium tuberculosis in which active TB disease arises from the progression of infection, reinfection, reactivation and relapse, while distinguishing infectious from non-infec- tious disease. We evaluated the effects of 5-yearly mass treatment using a range of parameter values to generate outcomes in uncertainty analysis.

RESULTS: Assuming population-wide treatment effectiveness for latent tuberculous infection and active TB of $\geqslant 90 \%$, annual TB incidence is expected to fall sharply at each 5-yearly round of treatment, approaching elimination in two decades. The model showed that the incidence rate is sensitive to the relapse rate after successful treatment of TB.

CONCLUSION: Mass treatment may help to eliminate $\mathrm{TB}$, at least for discrete or geographically isolated populations.

KEY WORDS: mass treatment; tuberculosis; elimination
THE ELIMINATION of tuberculosis (TB) at the global level by 2050 is an internationally agreed target. ${ }^{1}$ Elimination has been defined as an annual incidence rate of $<1$ new TB case per 1000000 population, a rate expected to prevent sustained transmission of Mycobacterium tuberculosis. ${ }^{2,3}$ However, TB elimination is clearly unrealistic without new tools and approaches. ${ }^{4}$ One thing is clear: a combined, simultaneous attack on active disease and latent tuberculous infection (LTBI) will be necessary. ${ }^{2,4}$

Active case finding plus mass prophylactic treat-

$\dagger^{\dagger}$ Deceased. ment against LTBI was evaluated by Comstock et al. among Alaskan Inuits in the 1960s. In a formal trial, $97 \%$ of individuals aged $>2$ months were randomised by household to receive 12 months of isoniazid (INH) prophylaxis or placebo, after screening with chest radiography to identify and treat those with active TB. ${ }^{5}$ Over a median 69 months of follow-up, $141 \mathrm{~TB}$ cases were diagnosed in the placebo arm $(n=$ 3017; crude incidence rate [IR] 812/100 000/year) and 58 in the INH arm $(n=3047$; IR 331/100 000/ year). Mass prophylactic treatment in the placebo arm subsequently resulted in further reductions, but not elimination, of incident TB cases over 19 years of follow-up. ${ }^{6,7}$ Horwitz et al. conducted a similar trial

Correspondence to: Philip Hill, Centre for International Health, Department of Preventive and Social Medicine, Faculty of Medicine, University of Otago, PO Box 913, Dunedin 9054, New Zealand. Tel: (+64) 3479 9462. Fax: (+64) 3 479 7298. email: Philip.hill@otago.ac.nz

Article submitted 4 January 2014. Final version accepted 18 April 2014. 
of mass prophylactic treatment along with active case finding in Greenland, in which $92 \%$ of eligible subjects participated. ${ }^{8}$ Adults in 76 paired villages were assigned, by village, to 6 months of INH prophylaxis $(n=3907)$ or placebo $(n=4174)$, after being medically assessed for TB disease. Over 6 years of active follow-up, there were 238 cases (IR 1015/ $100000 /$ year) in the INH arm and 323 cases (IR $1289 / 100000 /$ year) in the placebo arm.

It is important to ask why active case finding plus mass prophylactic treatment was so unsuccessful with respect to $\mathrm{TB}$ elimination. One strong possibility is that individuals with active TB disease were initially missed due to limitations in diagnostic procedures. An alternative mass treatment strategy that may overcome this limitation is the administration of a treatment regimen for $\mathrm{TB}$ disease to the whole population.

We aimed to assess whether such a strategy could lead to TB elimination in the well-defined, isolated population of Kiribati in the Pacific, where mass prophylactic treatment for leprosy has been undertaken previously with high rates of community participation. ${ }^{9}$

\section{METHODS}

\section{Strategy and rationale}

In this approach, a full course of anti-tuberculosis treatment is given to everyone: those with active disease (diagnosed and undiagnosed), those with LTBI and those who are not infected with $M$. tuberculosis. The rationale is as follows: all those with active, drug-susceptible disease will be treated and rendered non-infectious rapidly, those with drugsusceptible LTBI will have all residual tubercle bacilli killed, and those without infection will be prevented from getting infected at least while on treatment.

\section{Setting}

The Republic of Kiribati comprises 35 atolls and one raised coral island spread across 3.5 million $\mathrm{km}^{2}$ in the central tropical Pacific. Almost half of the population of approximately 100000 people lives in one urban area, South Tarawa. Kiribati is one of the poorest and least developed countries in the Pacific and is heavily reliant on external sources of income. It has a TB epidemic, with an annual case notification rate of approximately 335 new TB cases/100 000/ year since the mid-1990s (Figure 1A). Kiribati has a young population (Figure 1B), and the age group 1524 years has the largest number of cases (Figure 1C). The equally high rates of TB incidence among adults of all ages are indicative of ongoing transmission (Figure 1D). In a recent (2011) survey of a representative sample of 394 adults (aged $>18$ years), 45\% were tuberculin skin test positive, with a peak of $66 \%$ in those aged 45-54 years (unpublished data). The rate of increase in the percentage positive by age suggests an average annual risk of infection of about
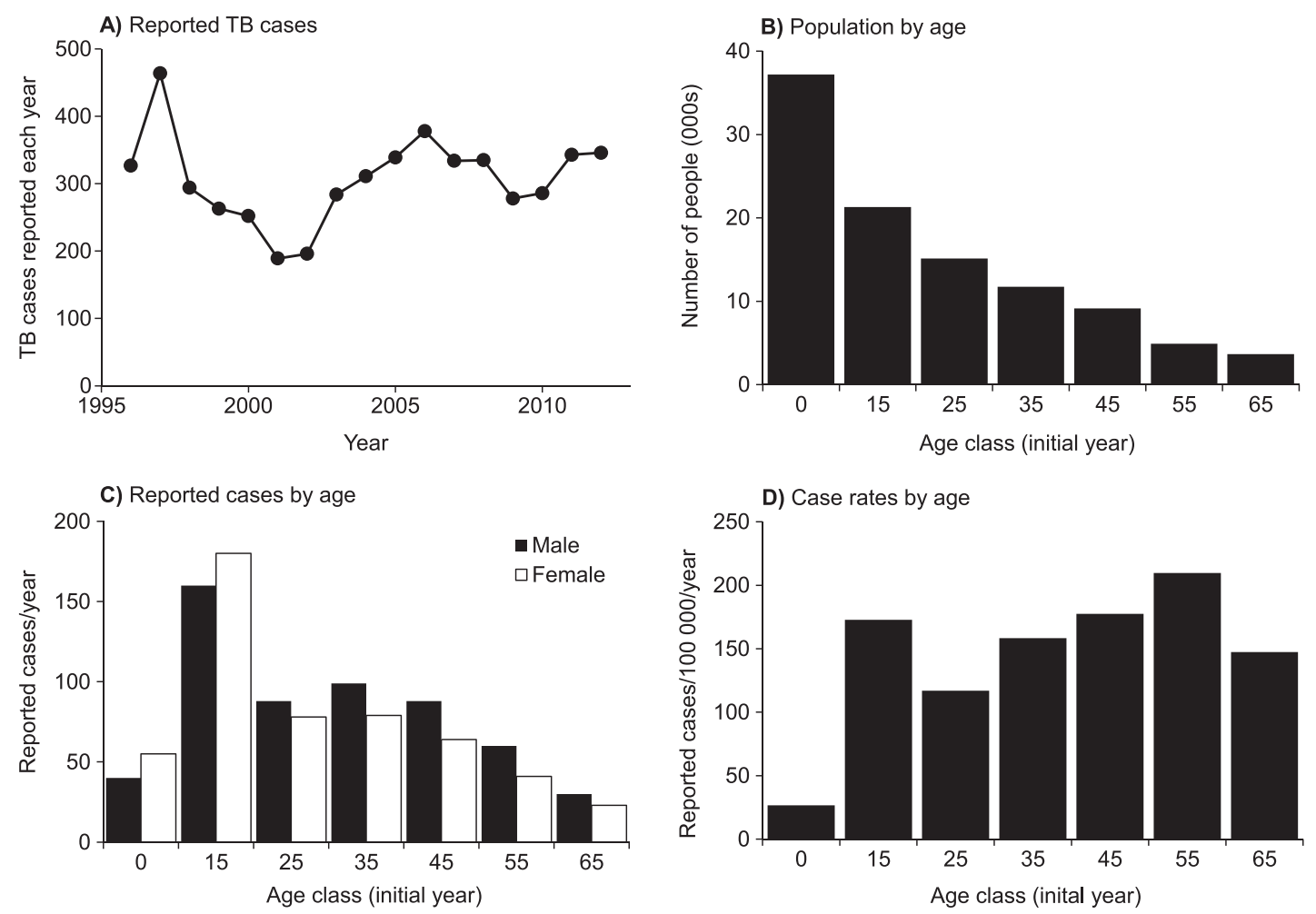

Figure 1 A) Total number of TB cases reported, Kiribati, 1995-2012; B) distribution of population by age; C) reported male and female TB cases by age; $\mathbf{D}$ ) total TB case rates by age. TB = tuberculosis. 
$2 \%$ over the past 50 years. Current TB control efforts include 6-month directly observed chemotherapy for TB cases, contact tracing, INH prophylaxis for contacts aged $<5$ years and those with diabetes, and screening of community members for $\mathrm{TB}$ in identified 'hotspots'. Although no representative surveys have been conducted, fewer than 100 human immunodeficiency virus positive individuals have ever been identified. Only one case of multidrugresistant TB (i.e., resistance to at least INH and rifampicin [RMP]) has been diagnosed, and fewer than 10 cases with monoresistance have been found (unpublished National Tuberculosis Control Programme [NTP] data).

As this study used routinely available data, ethical permission was not required.

\section{Model}

To determine the effects of mass treatment in Kiribati, we constructed a compartmental model of the life cycle of M. tuberculosis in which active TB disease, both infectious and non-infectious, arises from the progression of infection, reinfection, reactivation and relapse. ${ }^{4}$ Figure 2 shows the seven exclusive states included in the closed model (no migration). The corresponding set of coupled non-linear difference equations and model parameter values based on previous similar analyses ${ }^{4}$ are shown in the Appendix."

Using the solver function in Microsoft Excel (Microsoft, Redmond, WA, USA), we fitted the model to the series of annual case reports from Kiribati (Figure $1 \mathrm{~A}$ ) by varying the contact rate $\beta$, assuming that TB was stably endemic before any further intervention, at an average of 330 cases/ 100000 reported between 2000 and 2012. With the point estimates given in Appendix Table A, the basic case reproduction number of TB in Kiribati is $R_{0}=$ 4.3 and the annual risk of infection in the steady state is approximately $3 \%$.

To improve the effective treatment of active disease, we increased the rate of transfer of infectious and non-infectious TB cases to the cured state. The rate of transfer is determined by the product of the case detection rate and the proportion cured. Cases who are detected but not cured remain cases of active disease. To represent periodic rounds of mass treatment of the population in the model, a proportion $p$ of people $(0.6,0.8,0.9$ or 0.95$)$ in each of the classes $L f$ and $L s$ are moved instantly, at 5-year intervals, to 'treated latent' class $C_{l}$. At the same time, a proportion $p$ of $I$ and $N$ are moved to 'cured' class $C_{d}$, with a chance of relapse back to $I$ and $N$. To replicate the protective effect of treating non-infected

\footnotetext{
* The Appendix is available in the online version of this article, at http://www.ingentaconnect.com/content/iuatld/ijtld/2014/ 00000018/00000008/art00005
}

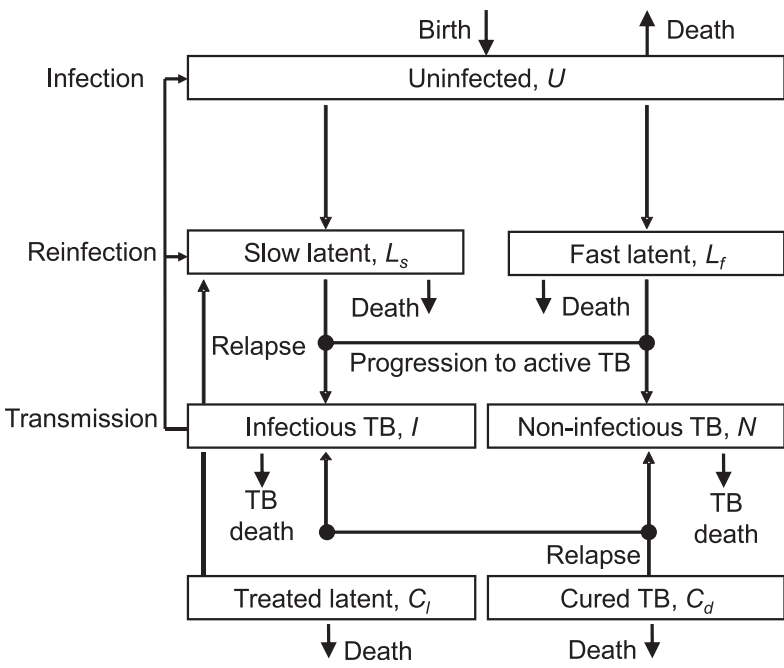

Figure 2 Flow chart of the compartmental mathematical model showing seven states, and the transitions in and out of each state in a closed population (no migration).

people, $U$, the contact rate $b$ between $I$ and $U$ was scaled down to $b(1-\sigma)$ for the 6-month duration of treatment, after which it reverts to $b$. Control variable $p$, our measure of effectiveness, is the product of population coverage and treatment efficacy per capita.

To investigate the factors responsible for uncertainty in outcomes, we generated 1000 Latin hypercube samples with a Mersenne twister (Palisade @Risk software; Palisade Corp, Ithaca, NY, USA) along a uniform distribution between low and high parameter values (Appendix Table A). The importance of each model parameter was measured by the correlation between values of that parameter and values of the primary outcome measure, the TB incidence rate in 2050.

\section{RESULTS}

\section{Routine TB control}

TB control as currently practised by the NTP is represented by a detection rate of cases $I$ and $N$ of 0.4 / year, so that the proportion of cases ever detected is 0.58 , with the proportion of cases cured set at 0.8 . Under these circumstances, the average duration of an infectious TB case is 1.5 years. To illustrate an improvement in routine TB control, the case detection rate is increased to 1.9 /year (0.96 of all cases ever detected) and the proportion cured increased to 0.85 . This reduces the average duration of an infectious case threefold, from 1.5 years to 0.5 years. This has the effect of forcing down the TB incidence rate at an average of $10 \%$ per year over the 10 years from 2015 to 2024 , to around $100 / 100000$ population by 2035 (Figure 3, line 3). To reduce the incidence by a factor of three in 20 years is significant progress. However, it is clear that no level of improvement to routine TB 


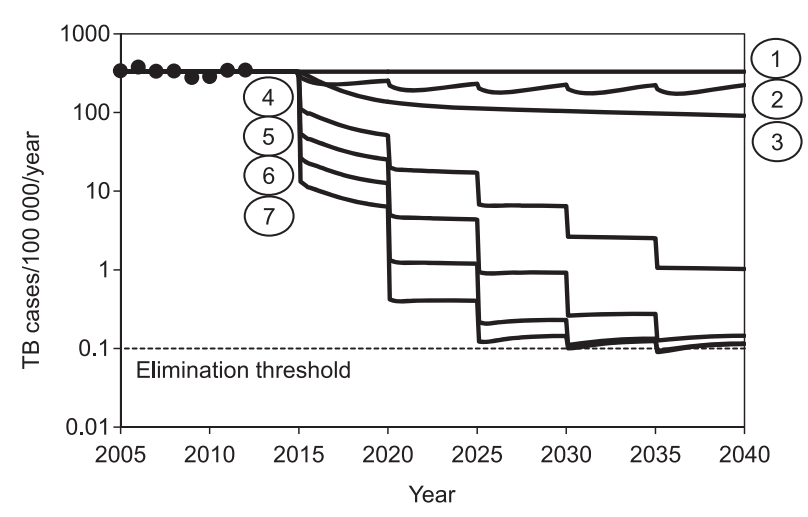

Figure 3 Expected reductions in TB incidence in Kiribati in response to five treatment scenarios. The black dots mark reported TB cases. Numbered lines represent: 1) continuation of the current strategy in which 0.58 of all cases are detected and 0.8 cured, 2) 5 -yearly mass treatment of active TB only, with 0.9 effectiveness, 3) improved routine treatment of active TB by the national TB control programme, raising the proportion detected to 0.96 and the proportion cured to $0.85,4-7$ ) mass treatment of the population with effectiveness of $\sigma=0.6,0.8,0.9$ and 0.95 , respectively. $\mathrm{TB}=$ tuberculosis.

control could eliminate TB in Kiribati within the space of a few decades. An alternative way to reduce incidence is by mass periodic treatment of active TB. However, a strategy of curing 0.9 of all TB cases every 5 years would be less successful than improving routine control in the example above (Figure 3, compare lines 2 and 3 ).

\section{Periodic mass treatment of the whole population}

In the calculations illustrated in Figure 3, we explored the effects of $\sigma=0.6,0.8,0.9$ and 0.95 . With a treatment effectiveness of $\sigma=0.9$ for LTBI and active $\mathrm{TB}$, and the same proportion of non-infected people protected against infection, the annual TB incidence is expected to drop precipitously at each 5-yearly round of treatment, falling to the elimination threshold within two decades (by 2035, Figure 3, line 5). Improving treatment effectiveness to 0.95 would lead to elimination by 2030 . The lowest possible incidence rate to which lines converge is governed by the incidence of relapse after successful treatment of active TB.

\section{Uncertainty analysis}

The results of the sensitivity analysis of TB incidence rate in 2050 to each of the model parameters, where sensitivity is measured by the correlation coefficient, are presented in Appendix Figure A. The relapse rate after treatment of active TB is by far the most important determinant of TB incidence rate in 2050. With a per capita relapse rate higher than $10^{-5}$ per year, it would not be possible to eliminate TB by 2050. However, irrespective of whether or not the elimination threshold is reached, the analysis is robust to our main conclusion: periodic mass treatment is a far more effective way of reducing TB incidence than the routine treatment of active disease.

\section{DISCUSSION}

In this paper, we have used mathematical modelling to investigate whether mass treatment with a full course of anti-tuberculosis drugs could eliminate TB from what might be considered an ideal target population - a Pacific island nation with a poorly controlled TB epidemic. Assuming a high level of mass treatment effectiveness for LTBI and active TB $(\sigma \geqslant 0.9)$ and protection of non-infected people, the annual TB incidence is expected to fall precipitously at each 5-yearly round of treatment, approaching elimination in two decades.

We have obtained this result with a simple compartmental model of TB epidemiology. We do not therefore claim to make precise forecasts of when elimination could be achieved in Kiribati. For example, the lowest achievable incidence rate within the next few decades is sensitive to the relapse rate after treatment of active TB, which is not accurately known. It is exposed by this study as a crucial factor in TB elimination. The uncertainty surrounding these details does not detract from the key point of our analysis, which is that mass population treatment is a far more effective intervention than routine treatment of active TB. We do not propose that the former should replace the latter, but rather that mass treatment would be a powerful supplementary measure to cut $\mathrm{TB}$ incidence to a minimum within 2-3 decades.

A number of issues require careful consideration (Table) beyond a formal cost analysis, which is outside of the scope of this paper. First, shorter regimens could be considered. Those with LTBI are likely to be successfully treated after 3 months of a regimen that includes both RMP and INH. ${ }^{10}$ While relapse rates are lowest with 6 months of treatment, they are almost as low with regimens as short as 3 months' duration. ${ }^{11}$ Indeed, studies could address whether those with occult, asymptomatic disease could be safely treated with less than 6 months of treatment. It is also anticipated that new drug regimens for all $\mathrm{TB}$ disease will be shorter in the future and have fewer side effects. ${ }^{12}$

Second, the main concern with respect to the side effects of treatment is hepatotoxicity. Interpretation of the available data is complicated by a disconnect between biochemical indices and clinical manifestations of hepatotoxicity, ${ }^{13}$ the lack of a standardised approach to diagnosis and management, and huge variations in the reported risk. ${ }^{14}$ Reassuringly, a study of 752 Danish patients on anti-tuberculosis treatment showed that the drugs could be continued, or successfully reintroduced in full, in most patients in whom liver enzyme levels increased up to six times 
Table Issues to consider with respect to mass treatment for tuberculosis

Number of treatment cycles

- More than one cycle may be necessary

- Repeat cycle could be more selective

Duration of treatment

- Shorter regimens should be considered for those who are asymptomatic

- Future standard regimens for active disease may be shorter

Drug toxicity

- Hepatotoxicity is of significant concern; clinical monitoring may be acceptable

- Newer drug regimens may have less toxicity and would enhance acceptability

Possible exclusions

- Young infants are low risk with respect to transmission of infection and initiation of treatment could be delayed

- Pregnant women (for inclusion 6-12 months post-partum)

- Those with serious liver disease and other contraindications to anti-tuberculosis drugs

- Terminally ill

- Those permanently departing the country

Ethics

- Greater good vs. individual benefit

- Appropriate community engagement and consent processes

- Effects on other aspects of the health system and on vulnerable groups

- Avoidance of coercion

Surveillance

- Standardised surveillance for disease is necessary before and after treatment

- Active vs. passive case finding strategies

- Strategic tuberculin skin test surveys would provide a useful indicator of transmission (e.g., all primary school entrants)

- Operational research

Components of the project

- A project management plan is required including finances, procurement and distribution, recruitment and training of staff, communication, education, health promotion, protocols, information systems, roll out, evaluation and supervision

- New policies may need to be introduced e.g., border control

the upper limit of normal. ${ }^{15}$ Additional reassurance is provided from resource-poor countries, where the bulk of anti-tuberculosis treatment is provided without routine biochemical testing - there have not been large numbers of reported cases of fatal drug-induced hepatitis.

Third, consideration could be given to excluding certain groups from treatment. In their trial, Comstock et al. excluded children aged $<2$ months who had no known TB contact. ${ }^{5}$ Other groups that could also be considered for exclusion are shown in the Table.

Fourth, a comprehensive public health approach would be required. Standardised surveillance of active disease would be necessary before and after the intervention, and appropriate processes would be required for dealing with data. The project would also require public education and engagement, adequate finances and staff, overall project management, and reliable and timely monitoring, evaluation and reporting. Elimination from an island would only be theoretically possible if, after the whole population has received treatment, they are no longer exposed to M. tuberculosis. Those persons who travel back and forth to the islands (e.g., for trade, education, etc.) and new immigrants would therefore need to be considered for treatment.

Fifth, there are important ethical principles to consider with any mass treatment strategy. ${ }^{16}$ Major issues include how to weigh population benefit against the lack of guaranteed benefit to any single individual and the potential to cause harm, how to engage in a sustained manner with the community and how to avoid coercion, which can be difficult to differentiate from persuasion in the context of a public health promotion and education campaign required for the project.

Mass treatment of the population for TB would have other non-TB benefits. For example, RMP is an effective prophylactic agent against leprosy, which remains endemic in many Pacific countries, presumably through clearance of nasal carriage. ${ }^{17}$ As mentioned above, mass prophylactic treatment for leprosy was undertaken in Kiribati in the 1990s, with very high rates of community participation of over $90 \%$. 9

Providing anti-tuberculosis treatment to the whole population could in theory eliminate TB in an island nation such as Kiribati, without any other public health actions and without improved diagnostic tests. Sub-total coverage and the potential for future relapse with current anti-tuberculosis treatment implies that more than one round of treatment is required. While there are a number of issues that need to be considered, this approach is likely to become more feasible with the availability of more effective, shorter and safer drug regimens. In anticipation of this, a number of preliminary studies could be conducted specifically to facilitate such an approach. A Pacific Island nation such as Kiribati has great potential to host preparatory studies with a view to a mass treatment approach in the future.

\section{Acknowledgements}

The views expressed in this article are those of the co-authors and do not necessarily represent the views of the World Health Organization and the other institutions for which they work.

Conflict of interest: none declared.

\section{References}

1 World Health Organization. The global plan to stop TB 20112015: transforming the fight towards elimination of tuberculosis. Geneva, Switzerland: WHO, Stop TB Partnership, 2010.

2 Dye C, Williams B G. Eliminating human tuberculosis in the twenty-first century. J R Soc Interface 2008; 5: 653-662.

3 Dye C, Maher D, Weil D, Espinal M, Raviglione M. Targets for global tuberculosis control. Int J Tuberc Lung Dis 2006; 10: 460-462.

4 Dye C, Glaziou P, Floyd K, Raviglione M. Prospects for tuberculosis elimination. Ann Rev Pub Health 2013; 34: 271286.

5 Comstock G W, Ferebee S H, Hammes L M. A controlled trial 
of community-wide isoniazid prophylaxis in Alaska. Am Rev Respir Dis 1967; 95: 935-943.

6 Comstock G W, Woolpert S F. Preventive treatment of untreated, nonactive tuberculosis in an Eskimo population. Arch Environ Health 1972; 25: 333-337.

7 Comstock G W, Baum C, Snider D E, Jr. Isoniazid prophylaxis among Alaskan Eskimos: a final report of the Bethel isoniazid studies. Am Rev Respir Dis 1979; 119: 827-830.

8 Horwitz O, Wilbek E, Erickson P A. Epidemiological basis of tuberculosis eradication. 10. Longitudinal studies on the risk of tuberculosis in the general population of a low-prevalence area. Bull World Health Organ 1969; 41: 95-113.

9 Daulako E C. Population screening and mass chemoprophylaxis in Kiribati. Int J Lepr Other Mycobact Dis 1999; 67 (Suppl): S23-S25.

10 Sterling T R, Villarino M E, Borisov A S, et al. Three months of rifapentine and isoniazid for latent tuberculosis infection. $\mathrm{N}$ Engl J Med 2011; 365: 2155-2166.

11 Gelband H. Regimens of less than six months for treating tuberculosis. Cochrane Database Syst Rev 2000; (2): CD001362.

12 Grosset J H, Singer T G, Bishai W R. New drugs for the treatment of tuberculosis: hope and reality. Int J Tuberc Lung Dis 2012; 16: 1005-1014.

13 Schlossberg D, Pritchett N, Nnumolu C. Asymptomatic hepatotoxicity in patients treated for tuberculosis and latent tuberculosis. Infect Dis Clin Pract 2007; 15: 320-323.

14 Saukkonen J J, Cohn D L, Jasmer R M, et al. An official ATS statement: hepatotoxicity of antituberculosis therapy. Am J Respir Crit Care Med 2006; 174: 935-952.

15 Dossing M, Wilcke J T, Askgaard D S, Nybo B. Liver injury during antituberculosis treatment: an 11-year study. Tubercle Lung Dis 1996; 77: 335-340.

16 Nuffield Council on Bioethics. Public health: ethical issues. London, UK: Nuffield Council on Bioethics, 2007. http://www. nuffieldbioethics.org/public-health. Accessed May 2014.

17 Bakker M I, Hatta M, Kwenang A, et al. Prevention of leprosy using rifampicin as chemoprophylaxis. Am J Trop Med Hyg 2005; 72: 443-448. 


\section{APPENDIX}

The different equations describing the dynamics of the seven health states in Figure 1 are as follows. The notation implies, for uninfected people, that $U_{t+1}=$ $f\left(U_{t}, I_{t}, N_{t}\right)$, etc., for each of the seven states. The subscripts denoting time $(t, t+1)$ are dropped for clarity. Definitions of parameters are shown in Table A. This compartmental model describes the baseline epidemiology of $\mathrm{TB}$, before introducing the further interventions described in the main text.

Uninfected $(U)$

$=U+\left(-\beta I U-\mu U+\mu+\mu_{t} I+\mu_{n} N\right) \delta t$

Fast latent $\left(L_{f}\right)$

$=L_{f}+\left(\beta p I U-\left(\mu+v_{f}\right) L_{f}\right) \delta t$

Slow latent $\left(L_{s}\right)$

$=L_{s}+\left(\beta(1-p) I U-\left(\mu+v_{s}\right) L_{s}-\beta p x I L_{s}+\bar{\omega}_{l} C_{l}\right) \delta t$

Infectious TB $(I)$

$=I+\left(s v_{f} L_{f}+s v_{s} L_{s}-\left(\mu+\mu_{t}+\eta+\tau \mathrm{k}\right) I\right.$

$\left.+\beta p x s I L_{s}+s\left(\bar{\omega}_{d}+\beta p x I\right) C\right) \delta t$

Non-infectious TB $(N)$

$$
\begin{aligned}
= & N+\left((1-s) v_{f} L_{f}+(1-s) v_{s} L_{s}\right. \\
& -\left(\mu+\mu_{n}+\eta+\tau \mathrm{k}\right) N+\beta p x(1-s) I L_{s} \\
& \left.+(1-s)\left(\bar{\omega}_{d}+\beta p x I\right) C\right) \delta t
\end{aligned}
$$

Active TB treated with drugs $\left(C_{d}\right)$

$$
=C_{d}+\left((\eta+\tau \mathrm{k})(I+N)-\left(\mu+\bar{\omega}_{d}\right) C_{d}-\beta p x I C_{d}\right) \delta t
$$

The final state, consisting of people with latent tuberculous infection who have been successfully treated $\left(C_{l}\right)$, is created only by periodic mass treatment of $L_{f}$ and $L_{s}$, as described in the main text.

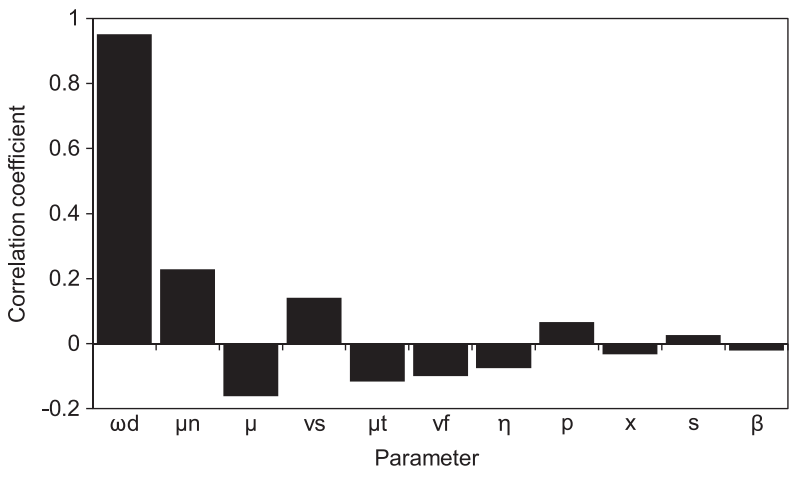

Figure A Sensitivity analysis of TB incidence rate in 2050 to each of the model parameters (see Table A), where sensitivity is measured by the correlation coefficient.

The rate of loss from this compartment is $-\left[\left(\mu+\bar{\omega}_{l}\right) C_{l}\right.$ $\left.+\beta p x I C_{l}\right] \delta t$.

The basic case reproduction number of this system is as follows:

$$
R_{0}=\beta s\left[\frac{p v_{f}}{\mu+v_{f}}+\frac{(1-p) v_{s}}{\mu+v_{s}}\right] \frac{c}{\mu+\mu_{t}+\eta+\tau \kappa}
$$

where $c$ is the average number of episodes of infectious TB suffered by each case, allowing for relapse from natural cure and from cure following drug treatment. The proportion of infectious cases that goes through one cycle of cure and relapse is:

\begin{tabular}{|c|c|c|c|c|c|}
\hline Parameter & value & Point & Low & High & Source \\
\hline Time step, year & $\delta \mathrm{t}$ & 0.1 & & & $\begin{array}{l}\text { Chosen to be short relative to } \\
\text { duration of other } \\
\text { epidemiological and population } \\
\text { processes }\end{array}$ \\
\hline Contact rate between infectious cases and others, /year & $\beta$ & 14.8 & 13.3 & 16.2 & $\begin{array}{l}\text { Fitted to generate initial incidence } \\
\text { rate } 330 / 100000 / \text { year }\end{array}$ \\
\hline Proportion infections becoming fast latent & $\mathrm{p}$ & 0.15 & 0.13 & 0.17 & 1 \\
\hline Rate of progression from latent to active TB, fast, /year & vf & 0.67 & 0.60 & 0.73 & 2 \\
\hline Rate of progression from latent to active TB, slow, /year & vs & 0.0020 & 0.0010 & 0.0030 & $1,3,4$ \\
\hline Death rate, not TB, /year & $\mu$ & 0.02 & 0.018 & 0.022 & $\begin{array}{l}\text { Based on } 50 \text { years of expected life } \\
\text { from age } 18 \text { (data.un.org) }\end{array}$ \\
\hline Death rate infectious TB, /year & $\mu \mathrm{t}$ & 0.15 & 0.10 & 0.20 & Fitted to generate a case fatality of \\
\hline Death rate non-infectious TB, /year & $\mu \mathrm{n}$ & 0.06 & 0.030 & 0.090 & $\begin{array}{l}0.23 \text { overall, and initial TB } \\
\text { mortality rate 50/100 000/year }\end{array}$ \\
\hline Natural cure rate all forms of TB, /year & $\eta$ & 0.20 & 0.15 & 0.25 & 1 \\
\hline Proportion incident TB cases that is infectious & s & 0.45 & 0.35 & 0.55 & 1 \\
\hline Proportion of reinfections that lead to active TB & $\mathrm{x}$ & 0.20 & 0.10 & 0.30 & 1,5 \\
\hline Relapse rate after cure of active TB, /year & $\pi \mathrm{d}$ & $1 e-05$ & $0 \mathrm{e}+00$ & $2 e-05$ & $\begin{array}{l}\text { Baseline estimate adjusted in } \\
\text { sensitivity analysis }\end{array}$ \\
\hline Relapse rate after treatment of latent TB, /year & $\pi \mid$ & 0 & 0 & 0 & Assumed \\
\hline
\end{tabular}

$$
c^{\prime}=\frac{(\eta+\tau \kappa) \bar{\omega}_{d}}{\left(\mu+\mu_{t}+\eta+\tau \kappa\right)\left(\mu+\bar{\omega}_{d}\right)}
$$

Therefore, the total number of cycles or episodes is $c=1 /(1-c)$.

Table A Model parameter values and their definitions 


\section{References}

1 Dye C, Garnett G P, Sleeman K, Williams B G. Prospects for worldwide tuberculosis control under the WHO DOTS strategy. Directly observed short-course therapy. Lancet 1998; 352: 18861891.

2 Dye C, Williams B G. Criteria for the control of drug-resistant tuberculosis. Proc Natl Acad Sci USA 2000; 97: 8180-8185.

3 Shea K M, Kammerer J S, Winston C A, Navin T R, Horsburgh C $\mathrm{R}$, Jr. Estimated rate of reactivation of latent tuberculosis infection in the United States, overall and by population subgroup. Am J Epidemiol 2014; 179: 216-225.

4 Horsburgh C R, Jr, O’Donnell M, Chamblee S, et al. Revisiting rates of reactivation tuberculosis: a population-based approach. Am J Respir Crit Care Med 2010; 182: 420-425.

5 Andrews J R, Noubary F, Walensky R P, Cerda R, Losina E, Horsburgh . Risk of progression to active tuberculosis following reinfection with Mycobacterium tuberculosis. Clin Infect Dis 2012; 54: 784-791. 
CONTEXTE : L'objectif mondial d'élimination de la tuberculose (TB) d'ici 2050 requiert de nouvelles approches. La recherche active des cas et le traitement préventif de masse ont été décevants. Nous envisageons le traitement anti-tuberculeux de masse complet comme une approche possible de l'élimination de la TB à Kiribati, une des îles du Pacifique où persiste une épidémie de TB à incidence élevée.

ОВJECTIF : Construire un modèle mathématique afin de prédire si le traitement de masse complet par médicaments antituberculeux serait susceptible d'éliminer la TB de la population de la République de Kiribati.

MÉTHODES : Nous avons construit un modèle compartimental en sept états du cycle de vie de Mycobacterium tuberculosis dans lequel la maladie tuberculeuse active résulte de la progression de l'infection, de la réinfection, de la réactivation et de la rechute, tout en distinguant la forme contagieuse et non contagieuse. Nous avons évalué les effets d'un traitement de masse tous les 5 ans, en utilisant une série de valeurs de paramètres afin de générer des résultats d'analyse d'incertitude.

RÉSULTATS : En estimant à $\geqslant 90 \%$ l'efficacité du traitement de toute une population pour une infection tuberculeuse latente et une TB active, l'incidence annuelle de la TB devrait chuter brutalement lors de chaque traitement de masse tous les 5 ans, arrivant à l'élimination en deux décennies. Le modèle a montré que l'incidence était sensible à la rechute après un traitement réussi de la TB.

CONCLUSION : Le traitement de masse pourrait contribuer à éliminer la TB, au moins dans des populations distinctes ou géographiquement isolées.
MARCO DE REFERENCIA: La meta mundial de eliminación de la tuberculosis (TB) en el 2050 exige nuevos enfoques. Los resultados de la búsqueda activa de casos aunada al tratamiento profiláctico colectivo han sido decepcionantes. Se propone el tratamiento antituberculoso completo colectivo como estrategia de eliminación en Kiribati, una isla del Pacífico con una epidemia de TB persistente de alta incidencia.

OBJETIVO: Construir un modelo matemático que permitiese predecir si un plan colectivo de tratamiento antituberculoso completo podría eliminar la TB en una población definida de la república de Kiribati.

MÉTODOS: Se construyó un modelo compartimental de siete estados clínicos de la infección por Mycobacterium tuberculosis, en el cual la enfermedad activa surge de la progresión de la infección, la reinfección, la reactivación o la recaída, distinguiendo la enfermedad contagiosa de la enfermedad no contagiosa. Mediante un análisis de incertidumbre se evaluaron los efectos de 5 años de tratamiento colectivo, al aplicar una serie de parámetros con el fin de generar desenlaces clínicos.

RESULTADOS: En la hipótesis de que la eficacia de un tratamiento a escala poblacional de la infección tuberculosa latente y de la enfermedad activa es $\geqslant 90 \%$, se prevé que la incidencia anual de TB disminuya de manera pronunciada en cada ronda de 5 años de tratamiento y se llegue cerca de la eliminación en dos decenios de aplicación. El modelo puso en evidencia que la tasa de incidencia es sensible a la tasa de recaída después de un tratamiento antituberculoso eficaz.

CONCLUSIón: El tratamiento colectivo podría contribuir a eliminar la TB, por lo menos en poblaciones definidas o geográficamente aisladas. 